\title{
Editorials
}

\section{Getting to the CORE of Weaning?}

Countless individuals undergo mechanical ventilation in intensive care units (ICUs) worldwide. Most of these patients undergo a process of separation from artificial ventilatory support, followed by removal of an endotracheal tube, which has traditionally been called weaning. While earlier efforts emphasized the gradual reduction of artificial support concomitantly with progressively greater assumption of the work of breathing by the patient, current approaches stress the timely recognition of readiness for liberation of the patient from the ventilator and airway. The challenge is to identify the earliest time when sufficient improvement has occurred for successful weaning and liberation, thereby minimizing unnecessary time on the ventilator with its accompanying added costs and risk of complications. An overly aggressive approach to early weaning can precipitate respiratory muscle fatigue and injury, however, and failed extubation adds risks associated with recurrent respiratory failure and re-intubation. The work by Delisle and colleagues, published in this issue of ReSPIRATORY CARE, ${ }^{1}$ examines the potential value of an integrated index in predicting the outcome of ventilator weaning.

See the Original Study on Page 1500

Despite years of investigation into optimizing methods to best determine whether the patient is ready to "fly on their own," extubation failure rates still hover in the $15 \%$ range. Early efforts to identify readiness for independent breathing focused on physiologic measurements at a point in time, rather than testing endurance per se. Two decades ago, Yang and Tobin found the ratio of respiratory frequency to tidal volume $\left(f / V_{T}\right)$, which has been called the rapid shallow breathing index (RSBI), to be the most sensitive and specific predictor of weaning success. ${ }^{2}$ An index that integrated thoracic compliance, respiratory rate, oxygenation, and maximum inspiratory pressure, which they called the CROP index, was nearly as robust. Current approaches to weaning incorporate additional conceptsspecifically, that a test of endurance, like a spontaneous breathing trial (SBT), adds value, and that a wide variety of pulmonary and non-pulmonary issues may impact the likelihood of successful liberation. Many issues are directly related to respiratory physiology, respiratory muscle strength and endurance, and effectiveness of gas exchange. However, other pulmonary factors, such as poor cough strength and excessive volume or tenacity of respiratory secretions are less easily quantified but can provoke ventilatory deterioration and re-intubation, regardless of chest mechanics and gas exchange. ${ }^{3}$ Not surprisingly, a variety of factors not directly related to the lungs, such as reduced level of consciousness or shock, can short-circuit successful liberation. In a recent randomized controlled trial (RCT), the addition of a scheduled interruption of sedative and analgesic medications to achieve an alert mental status significantly reduced duration of mechanical ventilation when combined with an SBT. ${ }^{4}$ Finally, issues related to airway patency after removal of the artificial airway, such as post-extubation stridor, can doom an otherwise successful attempt at liberation. ${ }^{5}$ These and other variables can be categorized and are listed along with common measures and selected comments in Table 1. The multi-factorial nature of extubation failure is highlighted in an analysis of patients who self-extubated. Independent risk factors for extubation failure included traditional variables such as use of controlled ventilation and hypoxemia, as well as tachycardia, multiple organ failure, altered mental status, and alkalosis. ${ }^{6}$

Implementing a structured approach to liberation from mechanical ventilation is attractive since it typically incorporates evidence-based approaches, increases the frequency and consistency of measurements and actions, reduces variability, and streamlines the process. Many protocols are team-based and capitalize on the expertise and ready availability of respiratory therapists and ICU nurses. The use of structured, multidisciplinary "weaning" programs has been associated with significant reductions in weaning time, duration of mechanical ventilation, and costs, as well as fewer re-intubations and other complications in numerous studies. . $^{70}$

The composition of such weaning protocols often varies by institution and has been the subject of considerable debate. As outlined in the 2001 American College of Chest Physicians/Society of Critical Care Medicine/American Association for Respiratory Care task force guidelines, most protocols include 3 major components: a daily screening of miscellaneous factors (see below), an SBT, and demonstration of ability to protect the airway and assessment of airway patency. ${ }^{10}$ In the task force guidelines the patient must pass all of the screening criteria before proceeding to the SBT: some reversal of the cause of ventilatory failure, adequate oxygenation $\left(\mathrm{P}_{\mathrm{aO}_{2}} / \mathrm{F}_{\mathrm{IO}_{2}} \geq 150-200 \mathrm{~mm} \mathrm{Hg}\right.$, PEEP $\leq 5-8 \mathrm{~cm} \mathrm{H}_{2} \mathrm{O}$, and $\left.\mathrm{F}_{\mathrm{IO}_{2}} \leq 0.4-0.5\right), \mathrm{pH}>7.25$, 
Getting to the CORE of Weaning?

Table 1. Common Components of Protocols to Guide Liberation from Mechanical Ventilation

\begin{tabular}{|c|c|c|}
\hline Variable & Measurements & Comments \\
\hline Medical stability & Hypotension, vasopressor requirement, $\mathrm{pH}$ & - \\
\hline Mental status & $\begin{array}{l}\text { Level of consciousness (sedation scale), continuous-infusion } \\
\text { sedation }\end{array}$ & $\begin{array}{l}\text { More alert state with daily interruption of sedation } \\
\text { improved success of spontaneous breathing trial } \\
\text { (SBT) in randomized controlled trial }\end{array}$ \\
\hline Oxygenation & $\mathrm{P}_{\mathrm{aO}} / \mathrm{F}_{\mathrm{IO}_{2}}, \mathrm{~F}_{\mathrm{IO}_{2}}, \mathrm{PEEP}$ & $\begin{array}{l}\text { Failure to meet oxygenation criteria in } 49 \% \text { of } \\
\text { successfully extubated patients in observational study }\end{array}$ \\
\hline Ventilation & $\mathrm{pH}+\mathrm{P}_{\mathrm{CO}_{2}}$ & - \\
\hline Lung mechanics & $\begin{array}{l}\text { Rapid shallow breathing index (RSBI) or frequency/tidal } \\
\text { volume }\left(\mathrm{f} / \mathrm{V}_{\mathrm{T}}\right) \text {, dynamic compliance }\end{array}$ & $\begin{array}{l}\text { Longer weaning duration if RSBI performed (vs no } \\
\text { RSBI) in randomized controlled trial (but duration of } \\
\text { ventilation same) }\end{array}$ \\
\hline Respiratory effort & $\begin{array}{l}\text { Airway-occlusion pressure } 0.1 \mathrm{~s} \text { after the start of inspiratory } \\
\text { flow }\left(\mathrm{P}_{0.1}\right), \mathrm{P}_{0.1} / \text { maximum inspiratory pressure }\end{array}$ & $\begin{array}{l}\mathrm{P}_{0.1} / \mathrm{P}_{\text {Imax }} \text { indexes effort-related change in occlusion } \\
\text { pressure to maximum pressure }\end{array}$ \\
\hline Respiratory muscle strength & $\mathrm{P}_{\text {Imax }}$ & - \\
\hline Endurance & SBT & $\begin{array}{l}\text { Considerable variability in SBT components: } \\
\text { Support during SBT (T-piece, continuous positive } \\
\text { airway pressure, pressure support, or automatic tube } \\
\text { compensation) } \\
\text { Duration of SBT (30, 60, or } 120 \text { min) } \\
\text { Termination criteria (tachypnea, reduced oxygen } \\
\text { saturation, tachycardia, hypertension or hypotension, } \\
\text { diaphoresis, distress-all with different thresholds } \\
\text { and durations) }\end{array}$ \\
\hline Respiratory secretions & Cough strength, sputum volume, sputum character & $\begin{array}{l}80 \% \text { extubation failure if heavy secretions, poor cough, } \\
\text { and poor mental status in observational study }\end{array}$ \\
\hline Airway patency & Cuff-leak test & $\begin{array}{l}\% \text { leak }=\% \text { decrease in exhaled } \mathrm{V}_{\mathrm{T}} \text { when } \\
\text { endotracheal tube cuff deflated vs } \mathrm{V}_{\mathrm{T}} \text { with cuff } \\
\text { inflated while receiving controlled ventilation with } \\
\mathrm{V}_{\mathrm{T}} \text { of } 10-12 \mathrm{~mL} / \mathrm{kg} \text {. } \\
\text { Discriminating } \% \text { leak thresholds to predict post- } \\
\text { extubation stridor }=12-24 \% \text { in various studies }\end{array}$ \\
\hline Miscellaneous & $\begin{array}{l}\text { Improving cause of respiratory failure, patient confidence in } \\
\text { extubation success }\end{array}$ & $\begin{array}{l}90 \% \text { success among patients confident of successful } \\
\text { extubation, vs } 45 \% \text { among non-confident patients }\end{array}$ \\
\hline \multirow[t]{2}{*}{ Integrative indexes } & $\begin{array}{l}\text { Compliance, respiration, oxygenation, pressure (CROP) } \\
\text { index }\end{array}$ & $\mathrm{CROP}=\left[\mathrm{C}_{\mathrm{dyn}} \times \mathrm{P}_{\mathrm{Imax}} \times\left(\mathrm{P}_{\mathrm{aO}_{2}} / \mathrm{P}_{\mathrm{AO}_{2}}\right)\right] / \mathrm{f}$ \\
\hline & Compliance, oxygenation, respiration, effort (CORE) index & $\mathrm{CORE}=\left[\mathrm{C}_{\mathrm{dyn}} \times\left(\mathrm{P}_{\mathrm{Imax}} / \mathrm{P}_{0.1}\right) \times\left(\mathrm{P}_{\mathrm{aO}_{2}} / \mathrm{P}_{\mathrm{AO}_{2}}\right)\right] / \mathrm{f}$ \\
\hline
\end{tabular}

hemodynamic stability with no more than minimal vasopressor support, and ability to initiate an inspiratory effort. ${ }^{11}$ As noted in Table 1, these and other variables are included in various weaning protocols. In most protocols the patient is required to pass all screening factors to proceed to SBT. It is noteworthy, however, that the use of an overly conservative protocol or inclusion of some criteria have been associated with delay in weaning and/or extubation. For example, in an RCT, the addition of RSBI to a standardized weaning protocol did not improve the accuracy of the protocol in predicting ability to successfully extubate, and actually prolonged the weaning process by
1 day. ${ }^{12}$ In an observational study, various factors were measured during weaning, and nearly half of all patients who were successfully weaned and extubated never passed the oxygenation screening criteria $\left(\mathrm{P}_{\mathrm{aO}_{2}} / \mathrm{F}_{\mathrm{IO}_{2}}>180 \mathrm{~mm} \mathrm{Hg}\right)$ despite their successful outcomes. ${ }^{13}$ The SBT is the pivotal component of most weaning protocols; however, there is considerable variability in how the key components of the SBT are applied. For example, duration ranges from $30 \mathrm{~min}$ to $120 \mathrm{~min}$ in published reports, and ventilatory support designed to overcome the added work of breathing through the airway ranges from no support with T-tube breathing to as much as $7-8 \mathrm{~cm} \mathrm{H}_{2} \mathrm{O}$ of pressure support. Automatic 
tube compensation is a ventilation mode that continuously adjusts applied pressure to changing flow-based airway resistance during each breath. ${ }^{14}$

Delisle and co-workers sought to examine the added value of a new integrative index, the CORE index (see Table 1), on the ability to predict the outcome of a trial of unassisted breathing using a 30-min T-tube trial. The CORE index is a modification of the CROP index, both of which incorporate dynamic compliance $\left(\mathrm{C}_{\mathrm{dyn}}\right), \mathrm{P}_{\mathrm{aO}_{2}}$, alveolar partial pressure of oxygen $\left(\mathrm{P}_{\mathrm{AO}_{2}}\right)$, and respiratory rate. The CORE index also includes the ratio of the maximum airway pressure $\left(\mathrm{P}_{\text {Imax }}\right)$ to the airway-occlusion pressure $0.1 \mathrm{~s}$ after the start of inspiratory flow $\left(\mathrm{P}_{0.1}\right)$ as a measure of respiratory effort, in place of $\mathrm{P}_{\text {Imax }}$ in CROP. The CORE index is calculated as:

$$
\text { CORE index }=\left[\text { Cdyn } \times\left(\mathrm{P}_{\operatorname{Imax}} / \mathrm{P}_{0.1}\right) \times\left(\mathrm{P}_{\mathrm{aO}_{2}} / \mathrm{P}_{\mathrm{AO}_{2}}\right)\right] / \mathrm{f}
$$

Delisle et al performed all physiologic measurements and arterial blood gas measurements to calculate the CORE index and other indexes at the conclusion of a $30 \mathrm{~min}$ SBT with pressure support of $8 \mathrm{~cm} \mathrm{H}_{2} \mathrm{O}$ and PEEP of $4 \mathrm{~cm} \mathrm{H}_{2} \mathrm{O}$, just before initiating a 30-min T-piece trial on $\mathrm{F}_{\mathrm{IO}_{2}}$ of 0.4. Thus, the patient who has the most compliant lungs, greatest respiratory muscle strength, most effortless breathing, best oxygenation, and slowest respiratory rate at the end of $30 \mathrm{~min}$ of low-level pressure support has the highest CORE index. Delisle et al found that a CORE index $>8$ was strongly associated with successful tolerance of a subsequent 30-min Tpiece trial, with near perfect sensitivity and specificity, and was superior to the CROP index, $\mathrm{P}_{0.1}$, and RSBI.

Should the CORE index become the standard for weaning assessment? There are reasonable questions to ask before embracing a new approach. Does it add value? Is it feasible to do? Was it studied in a patient population similar to your own patients? Have the results been reproduced? Delisle et al addressed a modest goal of predicting success of a brief unassisted breathing trial as a form of SBT, and chose not to directly examine the more important outcome of successful extubation. The risk of a brief unsuccessful SBT is limited, but since the CORE index precisely predicted the outcome of unassisted breathing in the study by Delisle et al, perhaps an RCT of the CORE index versus SBT is warranted.

How about feasibility and ease of use? Delisle et al used a rather lengthy weaning protocol that included screening, performance of a 30-min pressure-support SBT, measurement of physiologic variables and arterial blood gas values, calculation of CORE and other indexes, and concluding with the 30-min T-piece trial. Performing all of the components of the CORE index, including measuring $\mathrm{P}_{\text {Imax }}$ and $\mathrm{P}_{0.1}$, obtaining a precisely timed arterial blood gas measurement, and making the calculations seems cumbersome. However, as ventilator software continues to be- come increasingly sophisticated, integrated direct measurement of variables such as $\mathrm{P}_{0.1}$ - as done by Delisle et al—as well as on-board calculation of indexes such as CORE, will become more widely available. Computer-driven closed-loop physiologic measurements and automated pressure-support adjustment and performance of SBT reduced the duration of weaning and mechanical ventilation in a multicenter RCT. ${ }^{15}$

The generalizability and reproducibility of Delisle's results to other patients is important. We were struck by the very conservative screening criteria employed by Delisle et al, and wonder how many of their patients would still be intubated and ventilated in other ICUs. Specifically, among the various screening criteria, they required that an $\mathrm{F}_{\mathrm{IO}_{2}} \leq 0.4, \mathrm{PEEP} \leq 5 \mathrm{~cm} \mathrm{H} \mathrm{H}_{2} \mathrm{O}$, rectal temperature $<38^{\circ} \mathrm{C}$, hemoglobin $\geq 8 \mathrm{~g} / \mathrm{dL}$, and no continuous intravenous sedation/analgesia for at least 48 hours before enrollment in the study. The ventilator criteria are all firmly at the conservative end of other weaning criteria. The hemoglobin requirement is at odds with a widely practiced conservative transfusion policy that avoids erythrocyte transfusion for most patients unless hemoglobin is $<7 \mathrm{~g} / \mathrm{dL} .{ }^{16} \mathrm{Sim}-$ ilarly, a strategy of interruption of sedative/analgesic infusions followed by SBT often allows successful extubation within hours of stopping continuous sedative infusion. ${ }^{4}$ We wonder if the same impressive results would be seen if patients were enrolled at an earlier stage of recovery from respiratory failure-a question potentially answered in a multicenter RCT, as proposed by Delisle et al.

Delisle et al have added an important new tool for ventilator weaning, which integrates many facets of respiratory physiology into a single value. They found a striking concordance of a CORE index $>8$ with successful completion of a 30-min T-piece trial. A high CORE index signifies adequate oxygenation and comfortable breathing. Another option to physiologically documenting comfortable breathing may be to merely ask the patient if he or she is confident about the success of extubation. In a recent study, successful extubation was twice as frequent among patients who were confident of successful extubation than those who were not confident. ${ }^{17}$ Given the many factors involved in respiratory failure, it is unlikely that the art and science of weaning from mechanical ventilation can be distilled to just one equation, or a confident nod. Nevertheless, we eagerly await confirmatory studies that examine the performance of the CORE index in predicting successful liberation of patients from ventilator and airway in a broad population of critically ill patients at multiple centers.

Curtis N Sessler MD Catherine E Grossman MD Division of Pulmonary and Critical Care Medicine Virginia Commonwealth University Health System Richmond, Virginia 


\section{GetTing to the CORE of Weaning?}

\section{REFERENCES}

1. Delisle S, Francoeur M, Albert M, Ouellet P, Bellemare P, Arsenault P. Preliminary evaluation of a new index to predict the outcome of a spontaneous breathing trial. Respir Care 2011;56(10):1500-1505.

2. Yang KL, Tobin MJ. A prospective study of indexes predicting the outcome of trials of weaning from mechanical ventilation. N Engl J Med 1991;324(21):1445-1450.

3. Salam A, Tilluckdharry L, Amoateng-Adjepong Y, Manthous CA. Neurologic status, cough, secretions and extubation outcomes. Intensive Care Med 2004;30(7):1334-1339.

4. Girard TD, Kress JP, Fuchs BD, Thoamson JW, Schweickert WD, Pun BD, et al. Efficacy and safety of a paired sedation and ventilator weaning protocol for mechanically ventilated patients in intensive care (Awakening and Breathing Controlled trial): a randomised controlled trial. Lancet 2008;371(9607):126-134.

5. Jaber S, Chanques G, Matecki S, Ramonatxo M, Vergne C, Souche $\mathrm{B}$, et al. Post-extubation stridor in intensive care unit patients. Risk factors evaluation and importance of the cuff-leak test. Intensive Care Med 2003;29(1):69-74.

6. Listello D, Sessler CN. Unplanned extubation: clinical predictors for reintubation. Chest 1994;105(5):1496-1503.

7. Ely EW, Baker AM, Dunagan DP, Burke HL, Smith AC, Kelly PT, et al. Effect on the duration of mechanical ventilation of identifying patients capable of breathing spontaneously. N Engl J Med 1996; 335(25):1864-1869.

8. Kollef MH, Shapiro SD, Silver P, St John RE, Prentice D, Sauer S, et al. A randomized, controlled trial of protocol-directed versus physician-directed weaning from mechanical ventilation. Crit Care Med 1997;25(4):567-574.

The authors have disclosed no conflicts of interest.

Correspondence: Curtis N Sessler MD, Division of Pulmonary and Critical Care Medicine, Virginia Commonwealth University Health System, Medical College of Virginia Campus, Box 980050, Richmond VA 23298. E-mail: csessler@vcu.edu.

DOI: $10.4187 /$ respcare. 01581
9. Marelich GP, Murin S, Battistella F, Inciardi J, Vierra T, Roby M. Protocol weaning of mechanical ventilation in medical and surgical patients by respiratory care practitioners and nurses: effect on weaning time and incidence of ventilator-associated pneumonia. Chest 2000;118(2):459-467.

10. Grap MJ, Strickland D, Tormey L, Keane K, Lubin S, Emerson J, et al. Collaborative practice: development, implementation, and evaluation of a weaning protocol for patients receiving mechanical ventilation. Am J Crit Care 2003;12(5):454-460.

11. MacIntyre NR, Cook DJ, Ely EW Jr, Epstein SK, Fink JB, Heffner $\mathrm{JE}$, et al. Evidence-based guidelines for weaning and discontinuing ventilatory support: a collective task force facilitated by the American College of Chest Physicians; the American Association for Respiratory Care; and the American College of Critical Care Medicine. Chest 2001;120(6 Suppl):375S-395S.

12. Tanios MA, Nevins ML, Hendra KP, Cardinal P, Allan JE, Naumova EN, Epstein SK. A randomized controlled trial of the role of weaning predictors in clinical decision making. Crit Care Med 2006;34(10): 2530-2535.

13. Walsh TS, Dodds S, McArdle F. Evaluation of simple criteria to predict successful weaning from mechanical ventilation in intensive care patients. Br J Anaesth 2004;92(6):793-799.

14. Cohen JD, Shapiro M, Grozovski E, Vev S, Fisher H, Singer P. Extubation outcome following a spontaneous breathing trial with automatic tube compensation versus continuous positive airway pressure. Crit Care Med 2006;34(3):682-686.

15. Lellouche F, Mancebo J, Jolliet P, Roeseler J, Schortgen F, Dojat M, et al. A multicenter randomized trial of computer-driven protocolized weaning from mechanical ventilation. Am J Respir Crit Care Med 2006;174(8):894-900

16. Hebert PC, Wells G, Blajchman MA, et al. A multicenter, randomized, controlled clinical trial of transfusion requirements in critical care. Transfusion Requirements in Critical Care investigators, Canadian Critical Care Trials Group. N Engl J Med 1999;340(6):409417. Erratum in: N Engl J Med 1999;340(13):1056.

17. Perren A, Previsdomini M, Llamas M, Cerutti B, Gyorki S, Merlani $\mathrm{G}$, Jolliet P. Patients' prediction of extubation success. Intensive Care Med 2010;36(12):2045-2052. 